بر رسى تحمل به شورى بوتهاى نسل F2 حاصل از تلاقى سه رقم برنج (Oryza sativa) در مرحله جوانهزنى

اسد معصومى اصل"'، زهره جههابكارى"، سكينه خليلى"، رضا اميرى فهليانى'

$$
\begin{aligned}
& \text { ' 'استاديار كروه زراعت و اصلاح نباتات، دانشكده كشاورزى، دانشخاه ياسوج }
\end{aligned}
$$

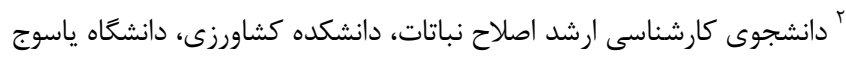

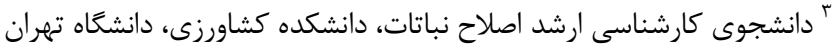

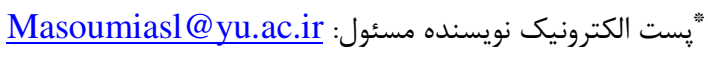

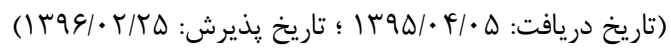

جكيده

تنش شورى از جمله تنشهاى محيطى است كه كشت برنج را محدود مىكند. بررسى وضعيت تحمل و

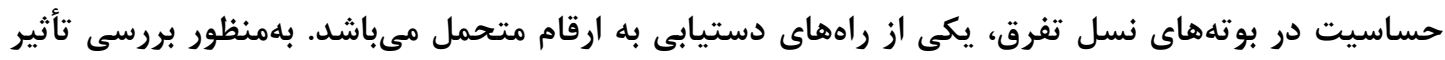

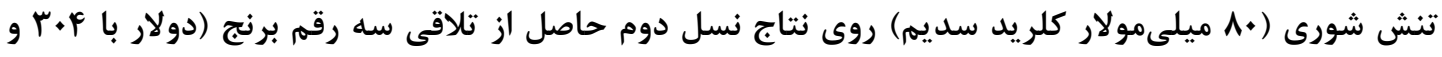

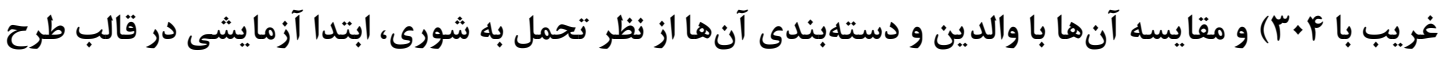

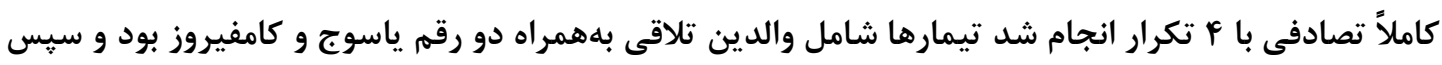

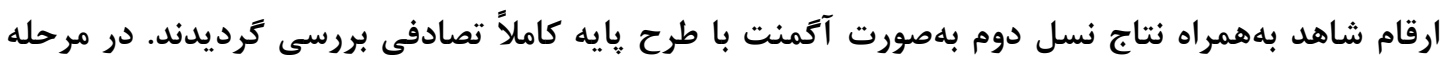

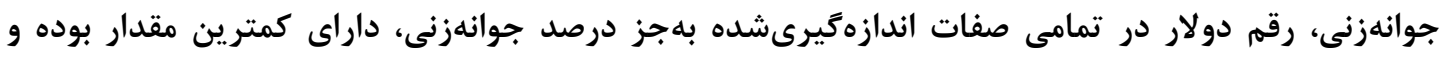

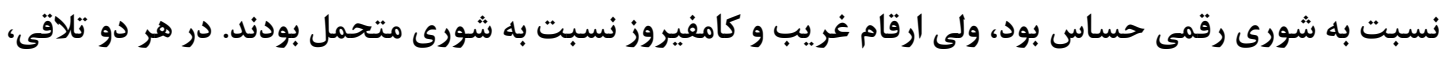

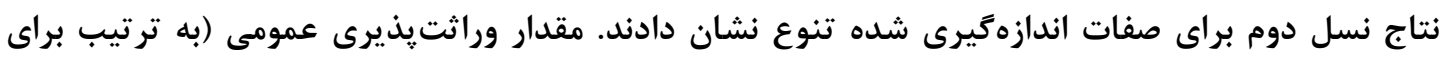

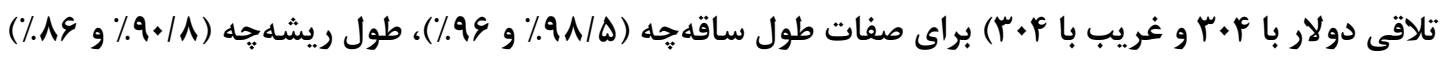

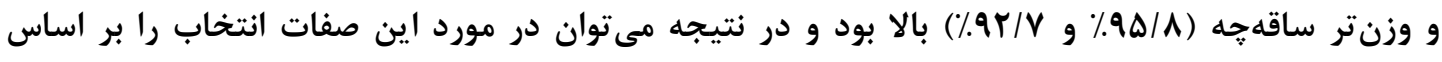

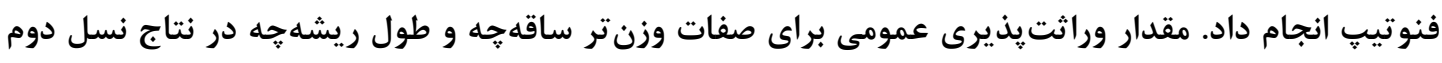

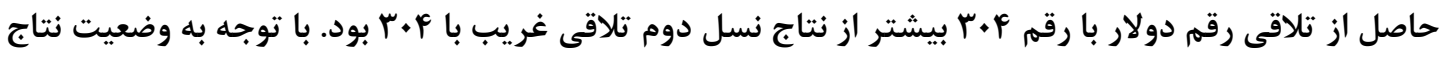

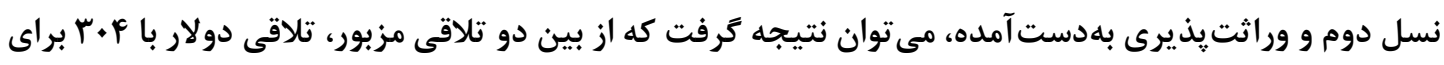

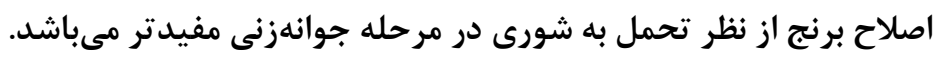

Fازههاى كليدى: برنج، تنش شورى، تنوع زنتيكى، نتاج جنبه هاى نوآورى: ا- براى اولين بار طرح آكمنت در تحقيقى آزمايشكاهى براى بررسى زنوتيبهاى بدون تكرار در نسل تفرق استفاده 
هميشه يكى از روشهاى اساسى مورد استفاده

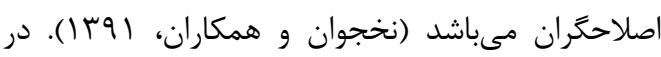
نتيجه تحقيقات انجامشده در زمينه غربال زنوتيبهان برنج در مقابل تنش شورى در كشورهاى مختلف دنيا،

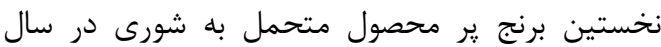

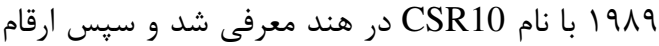

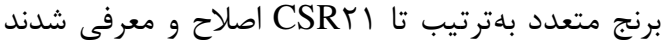

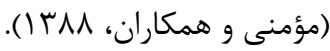

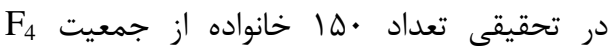

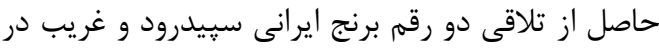

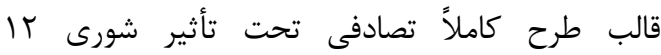
دسىزيمنس بر متر در مرحله كياهجه تحت شرايط كنترلشده، براى شناسايى لاينهاى متحمل به شورى فرى

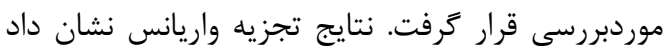

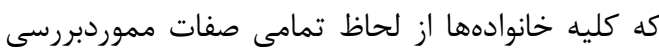
داراى تفاوت معنىدارى بوده و لذا وجود تنوع زنتيكى لدانى

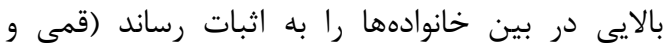

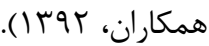

احمدىخواه و همكاران (سوץ|) در تحقيقى به اين نتيجه رسيدند كه تيمار شورى بر طول ساقهجه، ريشهجه و وزنتر كياهجه برنج رقم ندا كه از تلاقى ارقام محلى سنگ طارم با رقم اصلاحشده آمل بَ به دست آمده بود، اثر بسيار معنىدارى داشته است طورى كه

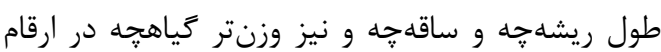

$$
\text { متحمل بيشتر بود. }
$$

طى تحقيق ديخرى جوانهزنى سه زنوتيب برنج به به نامهاى غريب، موسىطارم و ابجىبوجى در سطوح

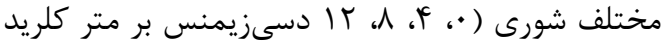
سديم) بررسى شد. با افزايش شورى، سرعت جوانهزنى

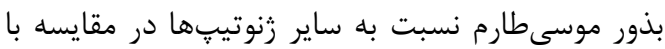
شاهد كاهش كمترى داشت، همجنين طول ساقهجه، ريشهجه، وزن خشك اين اندامها و نسبت ساقه به ريشه

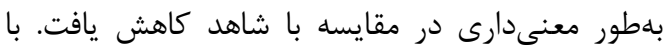
استناد به نتايج اين تحقيق، رقم موسىطارم بسيار

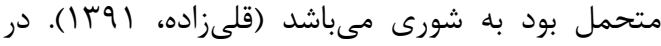
تحقيق ديخرى (معصومى اصل و همكاران، بوجr))، آزمايشى بهصورت فاكتوريل در قالب طرح كاملاً تصادفى (معصى

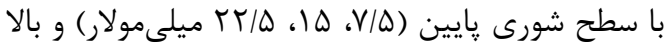

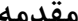

بryza sativa برنج كه كونه زراعى آن نام دارد، يكى از مهمترين محصولات

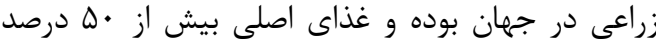

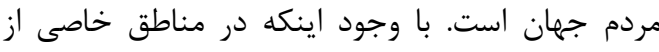
ايران به كشت و توليد اين محصول استراتزيك يرداخته مىشود، اما يكى از بزركترين واردكنند كان اين محصول

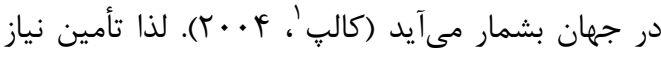
آينده كشور از طريق توليد ارقام يرمحصول با كيفيت مطلوب و ساز كار ضرورى است. تنش شورى، از جدىترين عوامل محدودكننده رشد و توليد كياهان زراعى (از جمله برنج) در مناطق ترنق خشك است. شورى خاك به دليل بالا بردن غلظت نمكدهاى محلول در خاك مرطوب اطراف ريشه و ايجاد فشار اسمزى بالا، جذب آب توسط ريشه را محدود و در در رئر نتيجه رشد گياهان زراعى را تحت تأثير قرار مىدهد

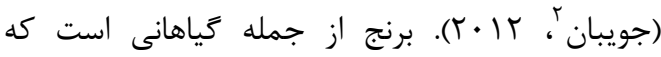
حساسيت زيادى به شورى داشته و اين حساسيت در آغاز مرحله رشد زايشى بيشتر از ساير مراحل است

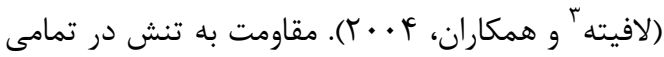

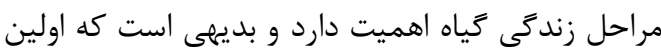

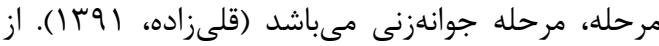
آنجا كه عملكرد از نظر كمى و كيفى به ميزان و درصد سبز شدن وابسته مىباشد، از اينرو مرحله جوانهزنى كياه، مرحله حساس و مهمى است كه مىتواند با استقرار مطلوب كياهجهها در فرآيند توليد، نقش مهرمى ايفا كند

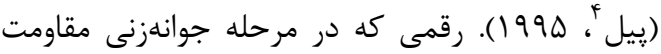

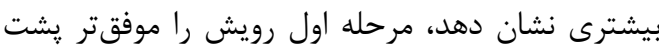
سر كذاشته و تراكم كشت كافى در واحد سطح خواهد

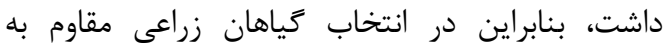
شورى، بايد مقاومت آنها در مرحله جوانهزنى و سبز

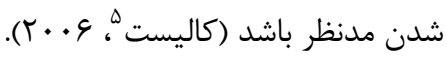

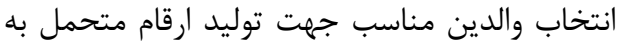
تنش كه داراى تركيبى از صفات مطلوب والدين باشند،

\footnotetext{
${ }^{1}$ Calpe

${ }^{2}$ Jouyban

${ }^{3}$ Laffitte

${ }^{4}$ Pill

${ }^{5}$ Calliste
} 
بررسى گرديدند (به نقل از شارما'، 991). نتاج نسل

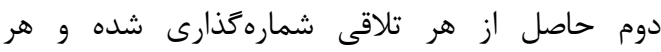
يترىديش با كاغذ صافى به جهار قسمت تقسيهم گرديد و در هر قسمت يك بذر از نتاج نسل دوم، قرار داده شد طورى كه امكان جابهجايى بذرها وجود نداشته باشد. به دليل اينكه در نسل تفرق هر بذرى يك زنوتيڤٍ است لذا در اين آزمايش براى بذرهاى نسل تفرق تكرار وجود

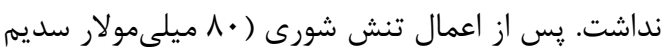

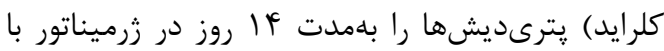
دماى ها د درجه سانتى طول ساقه

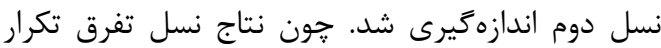
نداشته و هر بذر يك زنوتيٍ بود، لذا امكان محاسبه درصد و سرعت جوانهزنى وجود نداشت. بامنظور دستهبندى نتاج نسل دوم از نظر وضعيت تحمل به شورى، با توجه به نتايج آزمايش اول، بازه اطمينانى براى هر دو والد شركتكننده در تلاقىها با

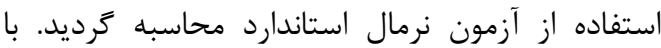

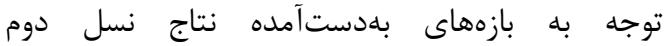
تقسيمبندى شدند. اين بازهها با استفاده از رابطه بـ محاسبه گرديدند. $\overline{\mathrm{d}}=\overline{\mathrm{x}} \pm z \sigma_{x}$ رابطه

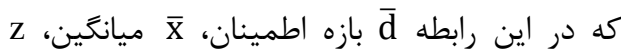

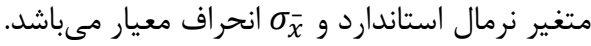

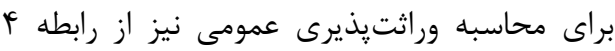
استفاده گرديد (به نقل از نخجوان و همكاران، (وس|):$$
\mathrm{H}_{\text {b.s }}=\left(\mathrm{VF}_{2}-\mathrm{E}_{\mathrm{w}}\right) / \mathrm{VF}_{2} \quad \text { رابطه }
$$

كه در اين رابطه h.s وراثتيذيرى عمومى، ${ }^{2}$ واريانس نسل دوم تفرق و Ew واريانس محيطى مى باشد. براى محاسبه واريانس محيطى فرمولهاى متعددى دوى ذكرشده كه در اين تحقيق از رابطه ه استفاده گرديد (به وناسيه نقل از نخجوان و همكاران، (وس (1):

$$
\mathrm{E}_{\mathrm{W}}=\frac{(\mathrm{Vp}+\mathrm{Vp})}{2} \quad \text { رابطه ه }
$$

در اين رابطه، V و V V V واريانس والدين تلاقى

$$
\text { مىباشد. }
$$

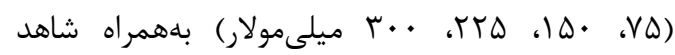
بهعنوان فاكتور اول و نه رقم برنج بهعنوان فاكتور دوم انجام شد. نتايج اين تحقيق نشان داد كه از نظر درصد جوانهزنى، رقم حسن سرايى برتر است؛ ولى از نظر

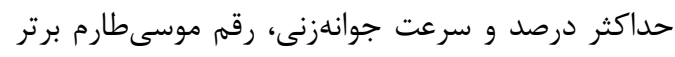
بود. هدف تحقيق حاضر، بررسى نسل تفرق حاصل از

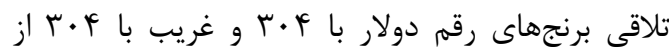
ل ل اظظ تحمل به شورى بود.

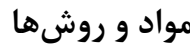

ابتدا آزمايشى در قالب طرح كاملاً تصادفى با باد

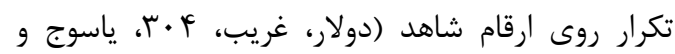

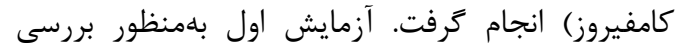
وضعيت تحمل و حساسيت والدين تلاقى بود تا از نتايج آن در آزمايش دوم استفاده گردد. در اين آزمايش يترىديشها و ساير وسايل موردنياز با استفاده از اتوكلاو

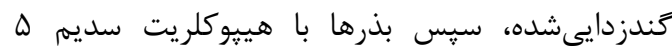

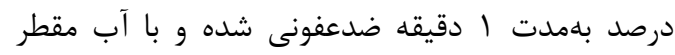
استريل شستشو گرديدند. از هر رقم ها عدد بذر در هر بر بـ

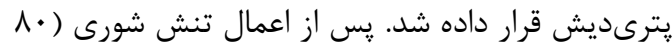

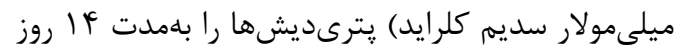
در زرميناتور با دماى ها ب درجه سانتى روز سوم تعداد بذرهاى جوانهزده شمارش گرديد. در نهايت، صفات طول و وزنتر و خشك ساقه

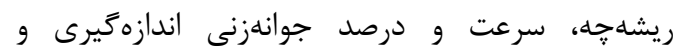
محاسبه گرديدند (رابطه 1 و Y) (به نقل از سوهانى،

:(ITVD

رابطه )

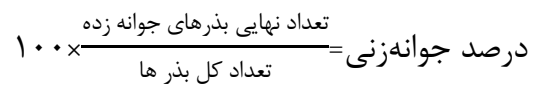

رابطه r: سرعت جوانهزنى رله

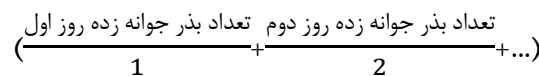
در آزمايش دوم، نتاج نسل دوم حاصل از تلاقى رقم

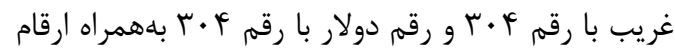

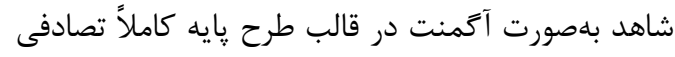

\section{${ }^{1}$ Sharma}


معصومىاصل و همكاران: بررسى تحمل به شورى بوتههاى نسل F2 حاصل از تلاقى سه رقم برنج...

جدول ا- ميانكين مربعات حاصل از تجزيه واريانس صفات مرتبط با جوانهزنى ارقام شاهد در سطح شورى •^ ميلىمولار

\begin{tabular}{|c|c|c|c|c|c|c|c|}
\hline وزن ريشه & ساقه & طول ريشه & طول ساقه & جوانهزنى & جوانهزنى درصد & آزادى & منبع تغييرات \\
\hline 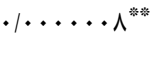 & 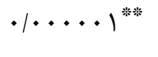 & Fr $/ \Delta \Lambda^{* * * *}$ & 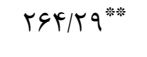 & 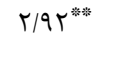 & 19Tr/A & f & رقم \\
\hline$\cdot 1 \cdot \cdots \cdot r$ & $\cdot / \cdots \cdots \cdot r$ & $19 / 94$ & I & .1 .91 & $f \cdot / \Lambda$ & 10 & خطا \\
\hline $\mid N / 4$ & $11 / \pi$ & $19 / \pi$ & $11 / 9$ & $9 / 1$ & $V / r$ & & ضريب تغييرات (درصد) \\
\hline
\end{tabular}

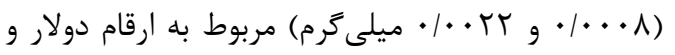
غريب بود. وزن خشك ريشه جه رقمهاى كامفيروز، ياسوج و دولار هر كدام با ساير ارقام تفاوت معنىدارى

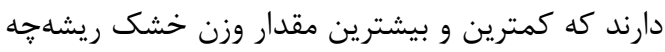
بهترتيب مربوط به ارقام دولار و كامفيروز بود. نتايج احمدى خواه و همكاران (سوس|) نيز نشان داد كه تيمار

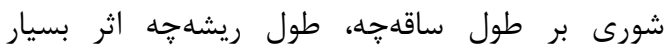
معنى دارى دارد، لذا مشاهده جنين تفاوتهايى در اثر اعمال تنش شورى در ارقام موردبررسى دور از انتظار نبود. طى ارزيابى مقاومت زنوتيڤٍهاى برنج ايرانى تحت

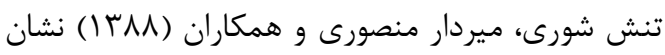
دادند كه تحت تنش شورى طول ساقه، طول ريشه، وزن

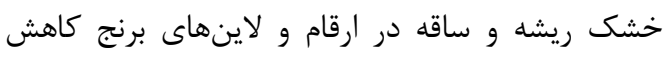
يافتند. در مجموع، مقايسه ميانگينها نشان داد كه رقم دولار، رقمى حساس به شورى است اما رقم غريب

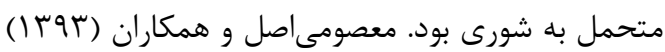

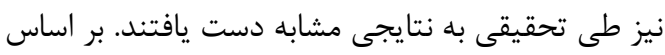

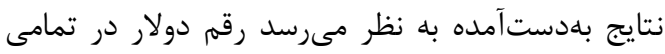
صفات اندازهكيرى شده بهجز درصد جوانهزنى، كمترين مقدار از هر صفت را داشته و رقمى حساس به شورى

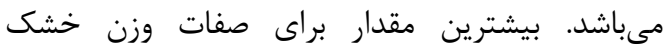
ريشه جه، درصد جوانهزنى و طول ريشه جه مربوط به رقم

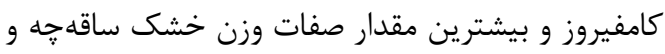
سرعت جوانهزنى مربوط به رقم غريب است. وزنتر ساقهجه ارقام غريب و ياسوج، وزنتر رقم ياسوج و در رَّر

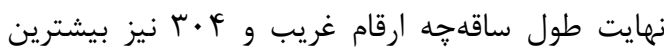

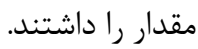

تجزيه دادهها و رسم نمودارها با استفاده از نرمافزار

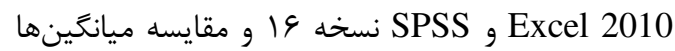
بر اساس آزمون دانكن در سطح احتمال ه درصد انجام شد.

\section{نتايج و بحث}

با توجه به جدول |، ارقام براى تمام صفات در سطح | درصد تفاوت معنىدارى نشان دادند. بيشترين ضريب تغييرات مربوط به صفت وزن خشك ريشه مقايسات ميانگينها نشان داد (جدول باء)، تحت تأثير تنش شورى درصد جوانهزنى رقم غريب با ساير

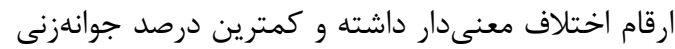

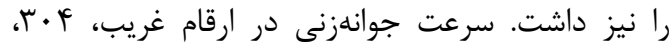
كامفيروز و ياسوج تحت تأثير شورى با يكديگر اختلاف معنىدارى ايجاد نكردند، ولى رقم دولار با ساير ارقام

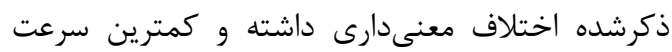
جوانهزنى را نشان داد كه احتمالاً به دليل حساسيت به شورى اين رقم است. طول ساقهجه رقمهاى كامفيروز و دولار هركدام با ساير ارقام تفاوت معنىدارى دارند كه كمترين و بيشترين مقدار طول ساقهجه بهترتيب مربوط

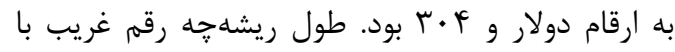

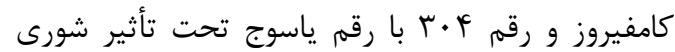
تفاوت معنىدارى نداشته ولى رقم دولار با ساير ارقام اختلاف معنى دارى دارد. كمترين و بيشترين مقدار طول ريشه جه در شورى (l| و • P ميلىمتر) بهترتيب متعلق به ارقام دولار و كامفيروز بود. براى صفت وزن خشك لمك ساقهجه،، رقم دولار با ساير ارقام تفاوت معنى دارى دارد بـ برد و كمترين و بيشترين مقدار وزن خشك ساقه 


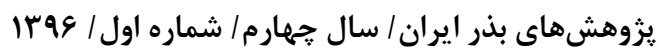

جدول r- مقايسه ميانگين ارقام از نظر صفات موردبررسى در سطح شورى •^ميلىمولار

\begin{tabular}{|c|c|c|c|c|c|c|}
\hline وزن خشك ريشه & وزن خشك ساقه & طول ريشه جه (ميلى متر) & طول ساقه جه & 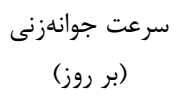 & جوانهزنى & \\
\hline$\cdot / \cdots \wedge c$ & . . .rra & ria & $f \cdot a$ & $\mathrm{r} / \mathrm{ra}$ & $f \& b$ & غريب \\
\hline$\cdot / \cdots 9 c$ & $\cdot / \cdot r \mathrm{ab}$ & r $\wedge \mathrm{ab}$ & $f \cdot a$ & $\mathrm{r} / \mathrm{la}$ & $1 \cdots a$ & $r \cdot \psi$ \\
\hline$\cdot / \cdot$ lfa & $\cdot / \cdot \mid \mathrm{IV} \mathrm{c}$ & rva & $r \wedge \mathrm{b}$ & $\mathrm{r} / \mathrm{ra}$ & $1 \cdots a$ & كامفيروز \\
\hline$\cdot / \cdots / 1 b$ & $\cdot / \cdots \wedge b c$ & $r \mid b$ & $\mathrm{rfa}$ & $r / V a$ & $9 \Delta \mathrm{a}$ & ياسوج \\
\hline$\cdot / \cdots r d$ & $\cdot / \cdots \wedge d$ & $1 \cdot c$ & ric & $1 / r b$ & $1 \cdots a$ & دولار \\
\hline
\end{tabular}

زنوتيبهاى با حداقل يك حرف مشابه در هر ستون بر اساس آزمون دانكن اختلاف معنى إرى در سطح احتمال خطاى ه درصد ندارند.

دستهاى شامل نتاج حساستر از دولار است. با توجه به

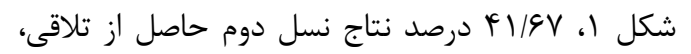
در صفت وزنتر ساقهجه مربوط به نتاج، مشابه والدين

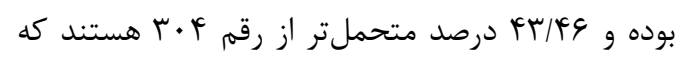

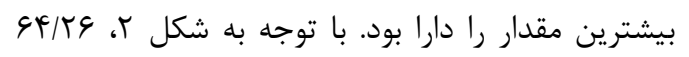

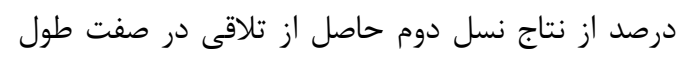

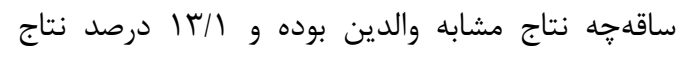

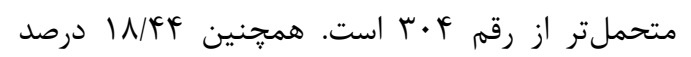
نتاج نسل دوم حاصل از تلاقى در صفت طول ريشهُ رده

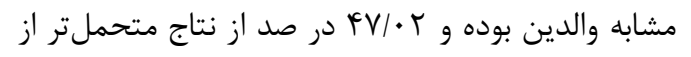

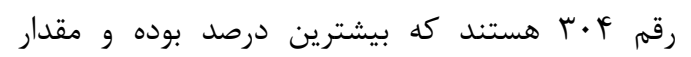
قابل ملاحظهاى محسوب مىشود (شكلهاى ) ، ب و ب).

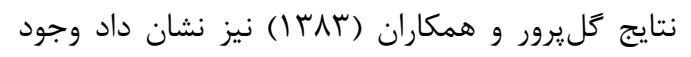
تفاوت معنى دار بين تيمارها (نسلها) از نظر كليه صفات

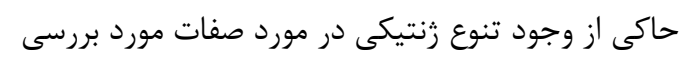
مىباشد.
بررسى نتاج نسل دوم حاصل از تلاقى رقم دولار با

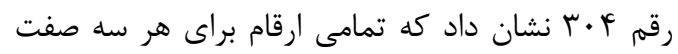

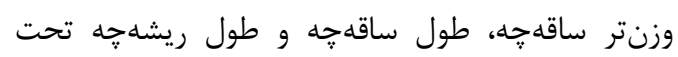
تأثير تنش شورى در سطح احتمال خطاى يك درصد

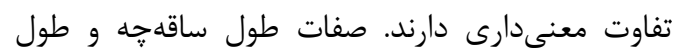

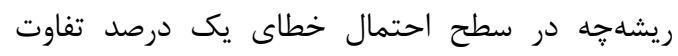
معنىدارى داشتند، ولى در مورد صفت وزنتر ساقهجه

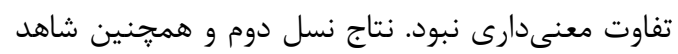

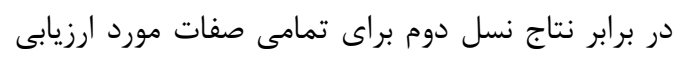

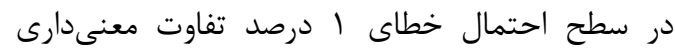

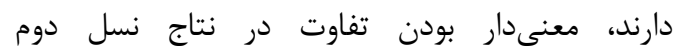

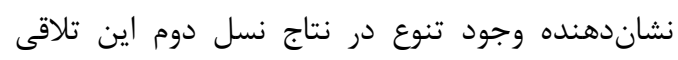

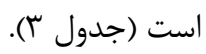
جدول بازههاى تعريفشده براى نتاج نسل دوم

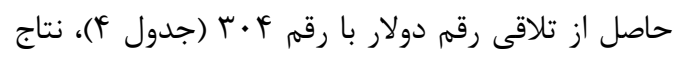
نسل دوم را در ه دسته قرار داد كه دو دسته شامل نتاج مشابه والدين، دسته سوم شامل نتاج حدواسط دو والد

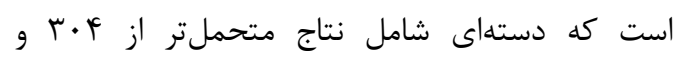

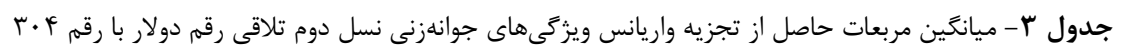

\begin{tabular}{|c|c|c|c|c|}
\hline طول ريشهجه & طول ساقهجه & وزنتر ساقه جه & درجه آزادى & منبع تغييرات \\
\hline$T \psi \cdot / \cdot V Q^{* * * a s}$ & $191 / \pi \varphi^{* * *}$ & . $/ \cdots r q^{* * * * *}$ & 194 & تمامى ارقام \\
\hline $\mid r \wedge / \wedge 9 V^{* * *}$ & 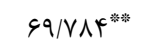 & $\cdot|\cdots \cdot| v^{\mathrm{ns}}$ & f & شاهد \\
\hline$r r \cdot / V r \varepsilon^{* * * *}$ & 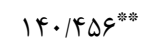 & $\cdot / \cdots r q^{* * * *}$ & 109 & نتاج نسل دوم \\
\hline r|rq/दrr":**: & $r \wedge r q / \mathcal{\Psi} \cdot \Delta^{* *: *}$ & $\cdot / \cdots \mid \wedge \Upsilon^{* * * * *}$ & 1 & شاهد در برابر نتاج نسل دوم \\
\hline rT/T & $1 . / r T q$ & $.1 \cdot \cdots \cdot \varphi$ & 10 & خطا \\
\hline
\end{tabular}


معصومى اصل و همكاران: بررسى تحمل به شورى بوتههاى نسل F2 حاصل از تلاقى سه رقم برنج...

جدول F - بازه تعريفشده براى تعيين وضعيت تحمل به شورى نتاج نسل دوم تلاقى رقم دولار با رقم F •r با سطح اطمينان هو درصد

\begin{tabular}{|c|c|c|c|c|c|}
\hline حساستر از رقم دولار & نتاج مشابه رقم دولار & حد واسط دو والد & نتاج مشابه رقم ץ •r & متحملتر از رقم †.r & $=$ \\
\hline$<\cdot 1 \cdot \cdot 1 f$ & $\cdot 1 \cdot \cdot 1 f_{-} \cdot 1 \cdot 1 r$ & $\cdot 1 \cdot 1 \mathrm{r} \cdot \cdot \cdot \cdot 1 \mathrm{~F}$ & $\cdot / \cdot 1 \mathrm{f}-\cdot \cdot \cdot 1 \mathrm{~V}$ & $\cdot 1 \cdot 1 \mathrm{~V}<$ & وزنتر ساقهجه (ميلى گرم) \\
\hline$<1 \cdot 11$ & $1 \cdot / 1-r F / r V$ & $r F / r V-r N / r$ & $r N / T-F F / T$ & $F F / T<$ & طول ساقهجه (ميلى متر) \\
\hline$<\mid f / \Delta$ & $\mid f / \Delta-19 / \pi$ & $\mid f / Q-1 N / q$ & ।N/q-r./VD & $r \cdot / V \Delta<$ & طول ريشه ֶِ (ميلىمتر) \\
\hline
\end{tabular}

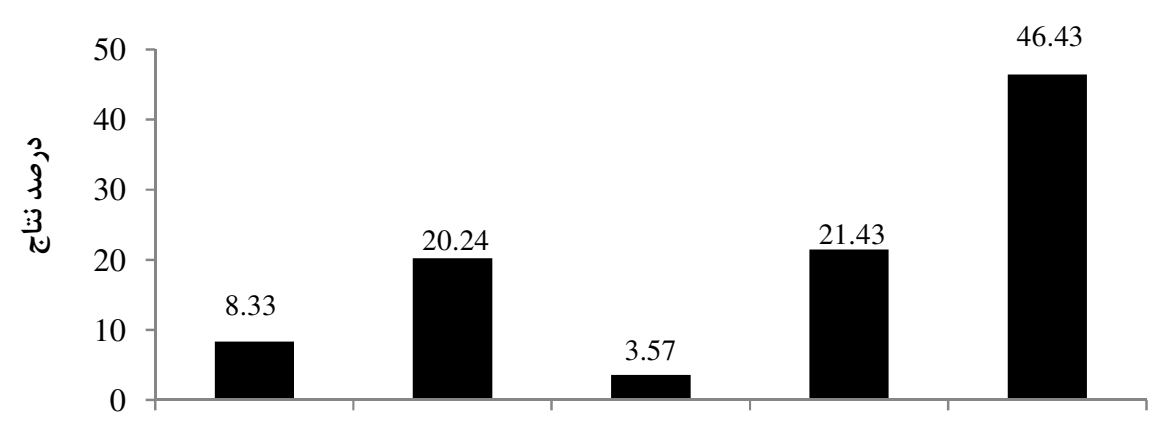

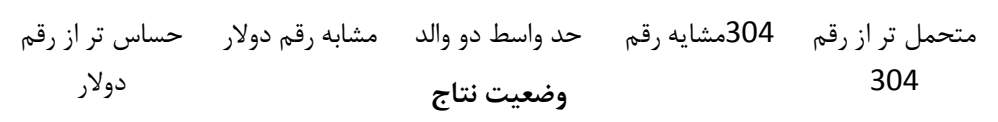

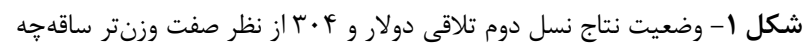

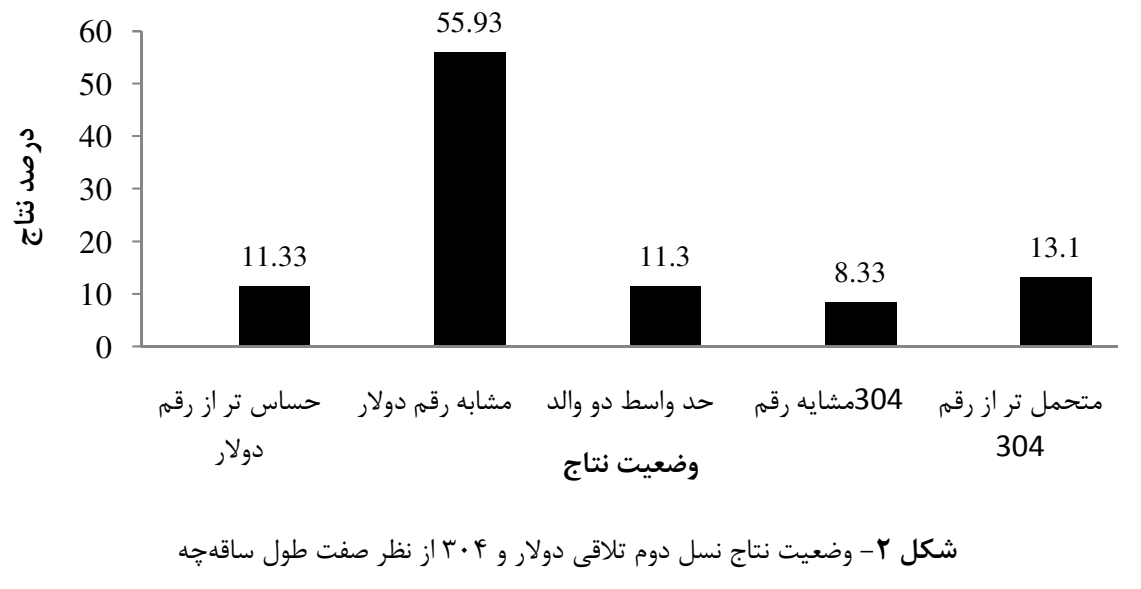




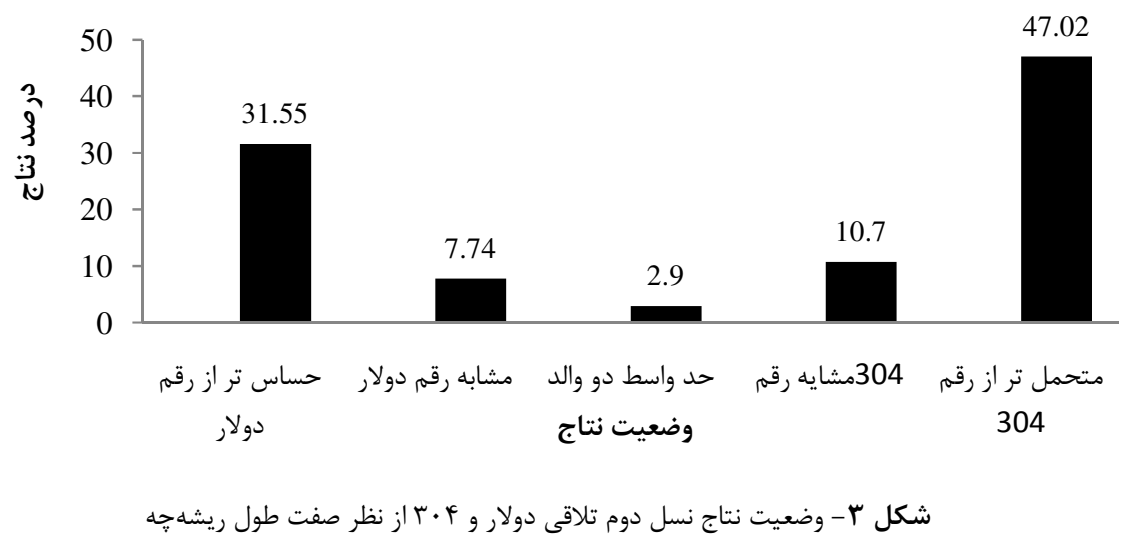

تفاوت در نتاج نسل دوم نشاندهنده تنوع مىباشد. با

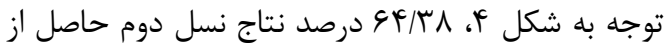
تلاقى فوق در صفت وزنتر ساقه

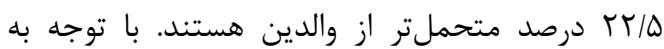
شكل ه، IV/D درصد از نتاج نسل دوم حاصل از تلاقى فوق در صفت طول ساقهجه مشابه والدين بوده و V/D

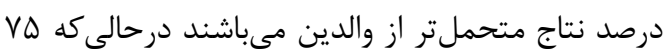
درصد از نتاج حساستر از والدين مىباشد. با توجه به

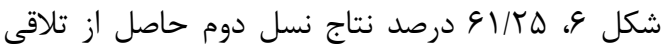
فوق در صفت طول ريشهجه مشابه والدين بوده و ז//س درصد نتاج نسل دوم متحملتر از والدين

$$
\text { مىباشند. }
$$

بررسى نتاج نسل دوم حاصل از تلاقى رقم غريب با رقم ץ +r نشان داد كه تمامى ارقام براى سه صفت وزنتر ساقه جه، طول ساقه تأثير تنش شورى در سطح احتمال خطاى يك درصد تفاوت معنى دارى دارند (جدول (ه). جدول بازههاى تعريفشده براى نتاج نسل دوم حاصل از تلاقى رقم

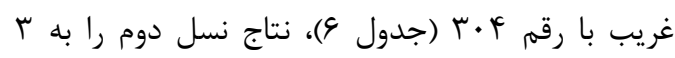
دسته تقسيمبندى كرد. ارقام شاهد براى وزنتر ساقه و طول ساقه جه با سطح احتمال خطاى ه درصد تفاوت داشته و در صفت طول ريشهجه تفاوت معنى دارى ايجاد نشده است. نتاج نسل دوم و ارقام شاهد در برابر نتاج نسل دوم براى صفات مورد ارزيابى در سطح احتمال خطاى يك درصد تفاوت معنىدارى دارند كه وجود برد

$$
\text { جدول هـ - ميانكَين مربعات حاصل از تجزيه واريانس ويزَى هاى جوانهزنى نسل دوم تلاقى غريب با ץ.ب }
$$

\begin{tabular}{|c|c|c|c|c|}
\hline طول ريشه جه & طول ساقهجه & وزنتر ساقه جه & درجه آزادى & منبع تغييرات \\
\hline 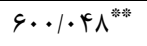 & $r \backslash \Lambda / \backslash \Delta \Delta^{\text {粰 }}$ & 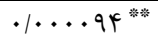 & IVT & تمامى ارقام \\
\hline $1 \cdot r / 1 T \xi^{\mathrm{ns}}$ & $G N / 4 r q^{*}$ & $\cdot 1 \cdot \cdots r \varphi^{*}$ & f & 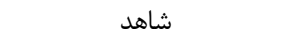 \\
\hline$G \cdot \Delta / T^{\prime} r^{* * * *}$ & $|r| Y /\left.T g\right|^{*}$ & $\cdot / \cdots \cdot q \uparrow^{* * * * *}$ & $19 V$ & نتاج نسل دوم \\
\hline $\mid V 9 / \Gamma \cdot r^{* * * *}$ & 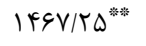 & $\cdot / \cdots r<q^{* * * *}$ & 1 & شاهد در برابر نتاج نسل دوم \\
\hline$\Delta r / A T F$ & IE/TTK & $\cdot 1 \cdot \cdots \cdot 4$ & 10 & خطا \\
\hline
\end{tabular}


معصومىاصل و همكاران: بررسى تحمل به شورى بوتههاى نسل F2 حاصل از تلاقى سه رقم برنج...

\begin{tabular}{|c|c|c|c|}
\hline حساستر از والدين & مشابه دو والد & متحملتر از والدين & صفت \\
\hline$<. / .1 f$ & $. / \cdot \mid \mathrm{F}-\cdot / \cdot \mathrm{rr}$ & $.1 \cdot r r<$ & وزنتر ساقهجه (ميلى گرم) \\
\hline$<\mu N / r$ & $r \Lambda / r-r g / \Lambda$ & $\forall q \mid \Lambda<$ & طول ساقه ֶه (ميلى متر) \\
\hline$<9 / 1$ & $q / 1-f \mid / D q$ & $|q| \Delta q<$ & طول ريشه ֶه (ميلىمتر) \\
\hline
\end{tabular}

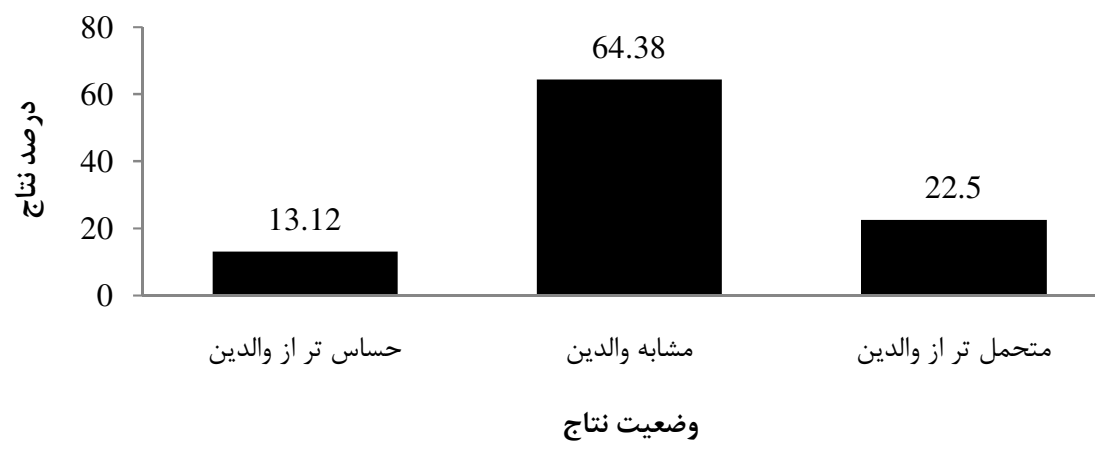

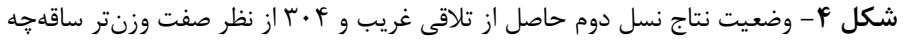

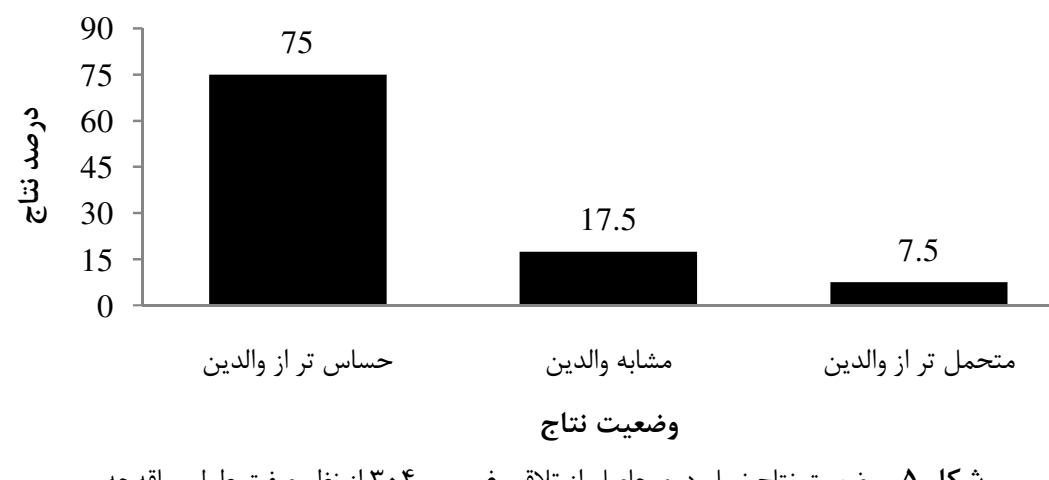

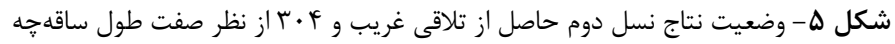

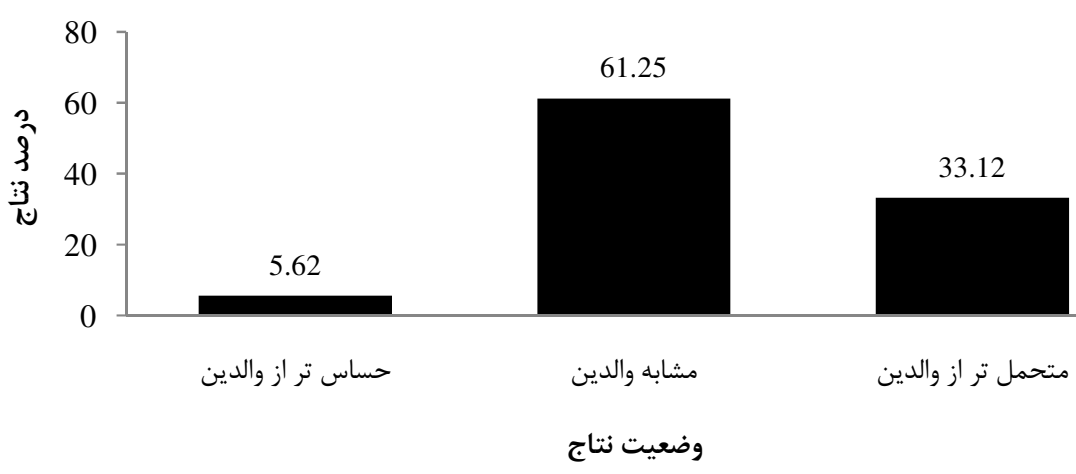

شكل 9- وضعيت نتاج نسل دوم حاصل از تلاقى غريب و \&.† از نظر صفت طول ريشهجه 
يزوهشهاى بذر ايران / سال جهارم/ شماره اول / צجسا

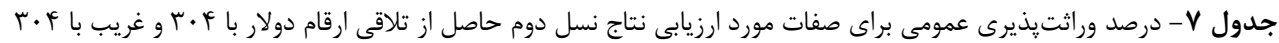

\begin{tabular}{|c|c|c|}
\hline 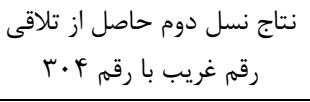 & نتاج نسل دوم حاصل از تلاقى دولار با رقم †. & صفات \\
\hline $9 T / V$ & $9 \Delta / \wedge$ & وزنتر ساقهجه (ميلى گرم) \\
\hline 99 & $9 \cdot 11$ & طول ساقهجه (ميلىمتر) \\
\hline$\wedge 9$ & $9 / / \Delta$ & طول ريشه ֶه (ميلىمتر ) \\
\hline
\end{tabular}

باشد نشاندهنده آن است كه اثر محيط كم بوده و

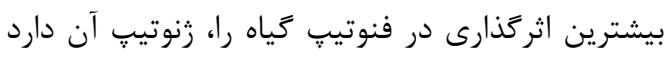

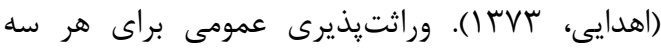

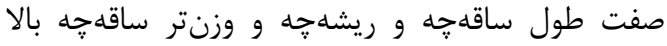
بوده و مقدار آن براى صفات وزنتر ساقهُه و طول

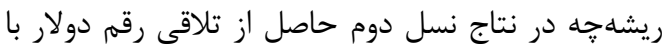

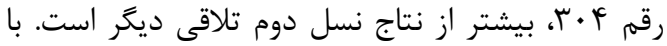
توجه به بالا بودن وراثتيذيرى عمومى در نتاج نسل دوم

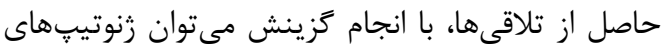

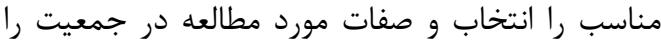

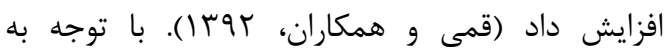
وضعيت نتاج نسل دوم و وراثتيذيرى بلهدستآمده، مىتوان نتيجه گرفت كه از بين دو تلاقى، تلاقى رقم دولار با رقم \& •r براى اصلاح برنج از نظر تحمل به شورى در مرحله جوانهزنى مفيدتر مىباشد.

\section{نتيجه}

در مجموع مىتوان گَفت روش دورگ ارقام حساس و متحمل، در ايجاد ارقام متحمل به شورى در برنج مىتواند موفق باشد و اينكه از بين دو تلاقى موردبررسى در اين تحقيق، تلاقى رقم خارجى دولار با

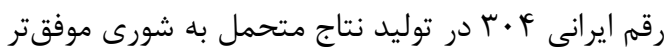
از تلاقى ديگر عمل كرده و در صفات طول ساقهجه و

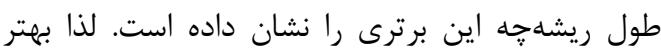

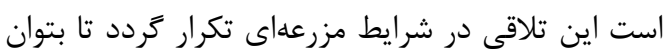
به نتايج بهتر و كاربردىترى دست يافت.
نتايج تجزيه واريانس نشان داد كه در هر دو تلاقى،

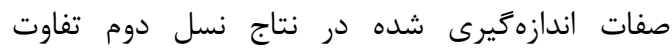
معنى دار با هم دارند و لذا وجود تنوع زنتيكى بالا درون كليه خانوادهها به اثبات مىرسد. قمى و همكاران

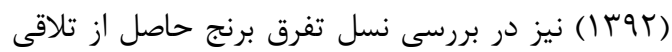

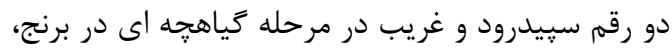
با بررسى صفات مختلف جوانهزنى و وضعيت رشدى گياهجههاى حاصله ارقام را امتيازبندى كرده و نشان دادند كه وزنتر و خشك ريشه گه و ساقه ֶه مى توانند در تشخيص ارقام متحمل و حساس موفق عمل كنند. در تحقيق حاضر نيز ما بر اساس صفات وزنتر و نيز طول ساقه گه و ريشهجه و تعريف بازههاى آمارى به شناسايى ارقام متحمل و حساس يرداختيم. نخجوان و و

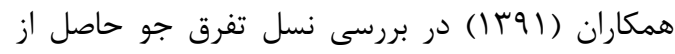

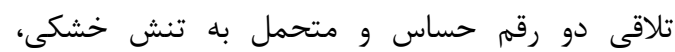

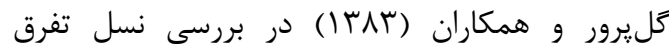
حاصل از تلاقى دو رقم گَندم متحمل و حساس به تنش

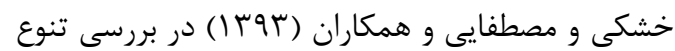
و تحمل به خشكى نسل F3 حاصل از تلاقى دو رقم كلرنگ اهلى و وحشى، وجود تنوع در بين نسلهاى

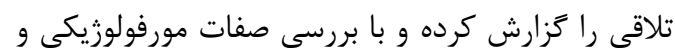
فيزيولوزيكى اثبات كردند كه روش دورگ ارقام متحمل موفق بوده و وراثتيذيرى خوبى براى صفات موردبر رسى گزارش كردند. با توجه به جدول V، وراثتيذيرى براى هر سه سه صفت مورد ارزيابى در نتاج نسل دوم حاصل از هر دو تلاقى بالا بود، هرجه ميزان وراثتيذيرى صفتى بالاتر 
Calliste, J.D. 2006. Mechanisms of salt tolerance: sodium, chloride and potassium homeostasis in two rice lines with different tolerance to salinity stress. Ph.D. Thesis. Faculty of Biology University of Bielefeld, Bielefeld, Germany, 143P.

Calpe, C. 2004. Rice situation update. International Rice Commission (IRC) newsletter, 53: 4-16.

Jouyban, Z. 2012. The Effects of Salt stress on plant growth. Technical Journal of Engineering and Applied Sciences, 2(1): 7-10.

Laffitte, H.R., Ismail, A., and Bennett, J. 2004. Abiotic stress tolerance in rice for Asia: progress and the future. In: Proceeding of 4th International Crop Science Congress, Brisbane, Australia. $1137 \mathrm{P}$.

Pill, W.G. 1995. Low water potential and pre-sowing germination treatments to improve seed quality. Seed Quality, 319-359.

Sharma, J.R. 1998. Statistical and biometrical techniques in plant breeding. New Age International Pvt Limited. New Dehli, 430P. 


\title{
An Investigation into the Salinity Tolerance of F2 Filial Plants Obtained from Three Rice (Oryza sativa L.) Cultivar Crosses in Germination Stage
}

\author{
Asad Masoumiasl ${ }^{1, *}$, Zohreh Chahabkari $^{2}$, Sakineh Khalili $^{3}$, Reza Amiri-Fahliani ${ }^{1}$ \\ ${ }^{1}$ Assistant Professor of Plant Breeding, Agriculture Faculty, Yasouj University, Yasouj, Iran \\ ${ }^{2}$ M.Sc. Student of Plant Breeding, Agriculture Faculty, Yasouj University, Yasouj, Iran \\ ${ }^{3}$ M.Sc. Student of Plant Breeding, Agriculture Faculty, Tehran University, Tehran, Iran \\ "Corresponding author, E-mail address: Masoumiasl@yu.ac.ir
}

(Received: 25.06.2016 ; Accepted: 15.05.2017)

\begin{abstract}
Salinity is one of the environmental stresses limiting rice cultivation. Evaluation of the tolerance and sensitivity of offsprings of segregated generations under salinity condition is one way of finding tolerant cultivars. In order to study the effects of salinity $(80 \mathrm{mM} \mathrm{NaCl})$ stress on the second generation offspring of crosses of three rice varieties (Dollars and Gharib with 304) and to compare them with their parents and their classification in terms of salinity stress, the first experiment was conducted, adopting a Completely Randomized Design with four replications (i.e., crossing parents with Yasouj and Kamfirooz varieties). In the second experiment, check cultivars and the second generation progeny were evaluated, using an augment with a completely randomized design. At the germination stage, the Dollar cultivar was sensitive to salinity stress because it had the lowest ratio of all traits except germination percentage. However, Gharib and Kamfirooz Cultivars were salt tolerant. In both crosses, second-generation offsprings showed genetic variations in terms of the traits measured. Broad-sense heritability values for Dollars $\times 304$ and Gharib $\times 304$ crosses for shoot height $(5.98 \%$ and $96 \%)$, root length $(8.90 \%$ and $86 \%)$ and shoot fresh weight $(8.95 \%$ and $7.92 \%)$, were relatively high, indicating that we can select these traits based on their phenotypes. General irritability for the shoot and root length traits in the second generation offsprings of Dollar and 304 crosses was higher than that of the second generation progeny of 304 and Gharib crosses. Based on these results, we concluded that for the purpose of improving salt tolerance at germination stage, 304 and Dollars crosses are more useful in rice breeding programs.
\end{abstract}

Keywords: Rice, Salinity stress, Genetic diversity, $F_{2}$ progenies

\section{Highlights:}

1- For the first time, an augment design was adopted in an experimental study to investigate the non-repeat genotypes in the segregating generations.

2- The tolerance and sensitivity of genotypes were evaluated, consistent with the definition of statistical intervals.

3- The results of this research led to the introduction of superior crossings for replications at the farm level. 